\title{
Improving energy efficiency of cyclone circuits in coal beneficiation plants by pump-storage systems
}

\author{
Lijun Zhang ${ }^{\mathrm{a}, *}$, Xiaohua Xia ${ }^{\mathrm{a}}$, Jiangfeng Zhang, ${ }^{\mathrm{a}, \mathrm{b}}$ \\ ${ }^{a}$ Department of Electrical, Electronic and Computer Engineering, University of Pretoria, Pretoria 0002, South Africa \\ ${ }^{b}$ Department of Electronic and Electrical Engineering, University of Strathclyde, Glasgow G1 1 XW, UK
}

\begin{abstract}
A pump storage system (PSS) is introduced to the coal preparation dense medium cyclone (DMC) plants to improve their energy efficiency while maintaining the required medium supply. The DMC processes are very energy intensive and inefficient because the medium supply pumps are constantly over-pumping. The PSS presented is to reduce energy consumption and cost by introducing an addition medium circulation loop. The corresponding pump operation optimization problem in the PSS scheme under time-based electricity tariff is formulated and solved, based on which the financial benefits of the design is investigated using life cycle cost analysis. A case study based on the operation status of a South African coal mine is carried out to verify the effectiveness of the proposed approach. It is demonstrated that the energy cost can be reduced by more than $50 \%$ in the studied case by introducing a $160 \mathrm{~m}^{3}$ storage tank. According to life cycle analysis, the PSS Option 1 yields an annual $38 \%$ reduction of the overall cost for the beneficiation plant with a payback period of 2.68 years.
\end{abstract}

Keywords: Coal beneficiation, pump-storage system, operation optimization, energy efficiency, life cycle cost analysis.

\section{Introduction}

Due to the fast increasing electricity demand, many countries are facing the threats of electricity blackout$\mathrm{s}$, which results in enormous economic losses [1]. To avoid such blackouts, studies are done in the field of rolling blackouts [2], demand response programs [3], etc. An energy efficiency improvement approach is proposed for the coal mining industry to address the energy shortage problem. Specifically, the coal cleaning dense medium cyclone (DMC) plants are studied.

It is a common practice that power stations are built right next to coal mines to save fuel transport cost. The coal mine is contracted to supply the power station while the power station provides electricity for the mine. Under such circumstances, improving energy efficiency of the coal mine leads to not only energy cost savings for the mine but also fuel cost reduction and improved supply capacity for the power station.

\footnotetext{
${ }^{*}$ Corresponding author. Email: lijun.zhang@up.ac.za. Tel: +270124204335 .
}

According to Eskom, the South African electricity public utility, mining industry takes about $15 \%$ of Eskom's annual output ${ }^{1}$. Moreover, electricity contributes $56 \%$ to mining industry's energy usage from 2002 to 2009 in South Africa according to available statistics $^{2}$. This implies that reducing electricity consumed by the coal mines contracted to power stations can offer a great opportunity for alleviating grid pressure. Yet, many coal washing plants in South Africa are built many years ago when electricity demand is low. The overall design is about limiting capital expenditure and operational downtime, rather than focusing on energy efficiency.

The pumping systems are operating at very low energy efficiency in coal mines. For instance, oversizing of pumps are very common and the operation of those pumps only considers operation safety. In the dense medium cyclone (DMC) coal beneficiation process, only $25 \%$ of the pumped medium are used

\footnotetext{
${ }^{1}$ Eskom 2011, Towards an energy efficient mining sector.

${ }^{2}$ Statistics of South Africa 2012, D0405.1.1-Energy accounts for South Africa, 2002-2009 (Discussion document).
} 
by the DMC while the other $75 \%$ simply flows back the corrected medium tank without being used.

Therefore, there is a great opportunity for reducing energy consumption of the DMC coal processing plant by energy-efficient pumping systems. This corresponds to one of the most important areas in mining industry in terms of energy efficiency improvementpumping systems - which were assessed to be able to save $14 \%$ of electricity cost if proper energy efficiency solutions are applied ${ }^{3}$.

Although many studies have been done on the power generating plants concerning generation dispatching $[4,5,6]$, maintenance scheduling $[7,8,9]$ and renewable energy integration [10], little attention has been paid to the power plants' contracted coal mines [11]. The focus of this study is to improve energy efficiency of the power station contracted coal mines so that the mine itself and the power station can benefit from such improvement.

In view of this, a pump storage system (PSS) is introduced to the DMC circuit. The PSS is used for two purposes. Firstly, it is used to add an additional medium circulation loop to the existing system to reduce the differential head of the pumps such that energy consumption can be reduced. Secondly, it is utilized to store the medium and consequently store energy when the grid demand is low in order to reduce energy cost and relief grid pressure.

Two options of PSS are presented in this study considering practical needs. The dynamics of the DMC process with the PSS options are modeled and the corresponding optimal operation problem of the proposed system is formulated under the time-based electricity tariff afterwards. The optimal operation problems considers the operation of multi-pumps under the time-based tariff. Though switching control of a single pump is not technically expensive, the operation of multi-pumps is complex and under investigation by many researchers $[12,13]$. Current practice for controlling such system resorts to rule-based methods $[14,15]$. In recent years, mathematical techniques are introduced to solve this problem, such as the optimization of pumping stations and air conditioning systems done in 2012 and 2013 [16, 17, 12, 18, 13].

In pump station studies, [17] presented an improved dynamic programming method for single-pump

\footnotetext{
${ }^{3}$ U.S. Department of Energy 2007, Mining Industry Energy Bandwidth Study.
}

operation in a pumping station in order to reduce energy cost. [12] extended the results of [17] to multipump operation with pump switching cost considered. The focus of [17] and [12] is to reduce the computation time incurred with the pump operation scheduling problem. In [18], multi-pump control of a pump station with the objective of minimizing pump switching frequency is presented. It gives a two stage control strategy which firstly determines the number of pumps that should be running and then decides which pump specifically to turn on (off). The pump operation only has ten states and thus the algorithm is a kind of switching control between different states.

Similarly, a decision-making procedure is proposed in [16] and the pump operation scheduling of a water distribution system is investigated in [13] to reduce energy consumption.

The operation problem is essentially a switching control problem which is mainly solved either by dynamic programming method $[17,12]$ or heuristic decision making methods $[16,18]$ in those studies. The introduction of time-based electricity tariffs that aim$\mathrm{s}$ to reduce peak load and relief grid pressure further imposes difficulties for the optimal operation of such multi-pump systems. In this study, mathematical formulation of the system dynamics and the corresponding optimal operation problem are presented. The optimal operation problem is treated as a binary integer programming problem and solved by the CPLEX optimization tool ${ }^{4}$. Optimization results show the advantages of the proposed system in terms of energy consumption and cost savings.

Take advantage of the operating cost of the system derived from the solution of the optimal operation problem, the financial feasibility and benefits of the proposed system is further evaluated. Life cycle cost analysis method is employed for this purpose, and it is shown that the proposed system results in preferable results in terms of both cost reduction and grid pressure alleviation.

It is also noted that the proposed approach does not affect the product quality of the cyclone separation process because it does not change the flow rate of medium supply to the DMC. Instead, it changes the medium supply circuit in configuration and operation to save energy.

The problem is further elaborated in Section 2 followed by two different configurations of the PSS

\footnotetext{
${ }^{4}$ ILOG 2008, CPLEX 11.0 User's Manual.
} 
in Section 3. After that, the system dynamics of the DMC plant with PSS is modeled in Section 4. Section 5 presents the formulation of the operation optimization problem. Life cycle analysis of the proposed design is done in Section 6. Case studies based on real-plant data are carried out in Section 7 to affirm the proposed system's financial viability and effectiveness in improving energy efficiency. Then conclusion is drawn in Section 8.

\section{Problem statement}

Coal preparation plant consists of several coal cleaning processes to wash the run-of-mine coal so that it can be transported to market [19]. This study focuses on improving energy efficiency of the dense medium cyclone separation processes such that the energy cost of the mine can be reduced and consequently reduce the fuel cost of its contracted power stations.

The schematic diagram of the cyclone separation process is shown in Fig. 1 [20]. It can be seen that raw coal and dense medium pumped from the corrected medium tank, which normally situated in the basement of the plant, are blended in the mixing box before entering the cyclone for separation.

In the cyclone process, the feed, mixture of raw coal and dense medium, enters tangentially near the top of the cylindrical section of the cyclone, thus forming a strong swirling flow. Centrifugal forces cause the rejects or high ash particles with high specific gravity to move towards the wall and to discharge in the underflow through the spigot. The lighter particles are caught in an upward stream and pass out as clean coal through the cyclone overflow outlet via the vortex finder.

The dense medium supplied to the cyclone is essential for the separation efficiency and product quality $[21,22]$. For each coal washing module, there is a corrected medium pump used to supply medium to the cyclone. The medium is pumped from the corrected medium tank to the distributor where it is split into two streams, one to the mixing box and the other flows back down to the corrected medium tank. The resulting clean coal and rejects are subject to drain and rinse screens to recover the medium and to yield clean coal.

One thing worth noting is that the part of medium that flows back down to the bottom of the plant is used in practice for operation safety reasons. Insufficient medium at the cyclone will result in drops of production rate and quality of the plant. Therefore, under-pumping is undesired and must be avoid at all cost. Therefore, plant operators always try to avoid under-pumping to maintain the quality of fine coal.

Current practice to maintain the coal quality is realized by pumping more medium than it is required by the cyclone separation process and the over-pumped medium simply overflows back to the corrected medium tank. The energy consumption of this over-pumping is wasted during the coal washing process.

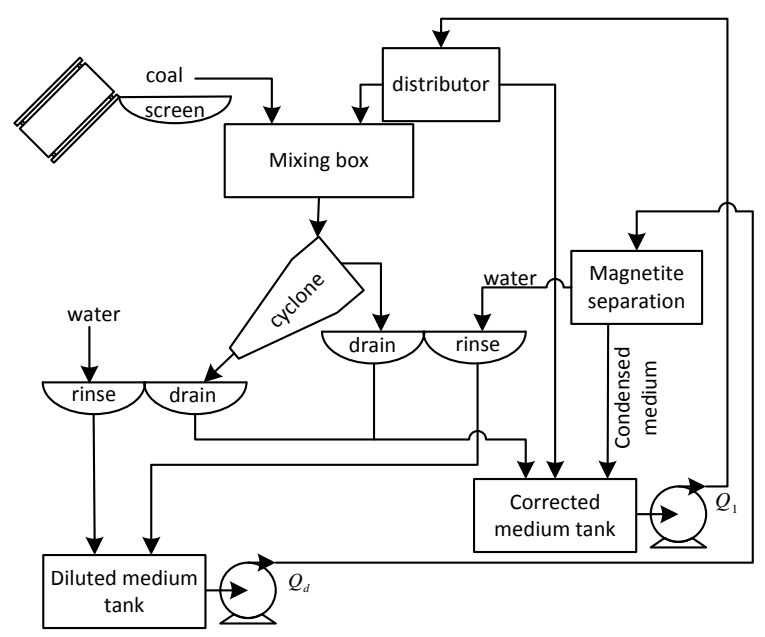

Figure 1: Flow chart of cyclone circuit

\section{Energy saving via PSS}

The PSS introduced aims to provide the plant with medium recirculation ability which allows the over-pumped medium to be pumped back to the distributor without flowing back down to the bottom of the plant. It is in this way that energy consumption and cost are reduced. Two different configurations of the PSS are proposed for the coal beneficiation plant and detailed in this section.

Changing the existing medium supply to the cyclone process is undesired as insufficient medium supply may result in product quality drop. Therefore, the proposed approach does not change the medium supply rate to the distributor, i.e., the flow rate of the dense medium pumped to the distributor is kept the same as that of the existing system. Instead, the dense medium circuit is changed in configuration and operation to reduce energy costs.

\subsection{PSS Option 1}

As a first option, a secondary corrected medium tank is added in the way of the downward flowing 
medium pipe to store the over-pumped medium and a pump is installed there to pump the medium back up to the distributor. Motivation of this configuration is that the differential head of the added pump is much less than the originally used corrected medium pump, therefore the power and energy consumption of the pump can be reduced. This configuration is shown in Fig. 2. The added tank and pump forms an additional medium circulation loop in the system as shown in Fig. 2 and are denoted by T2 and P2 from here after.

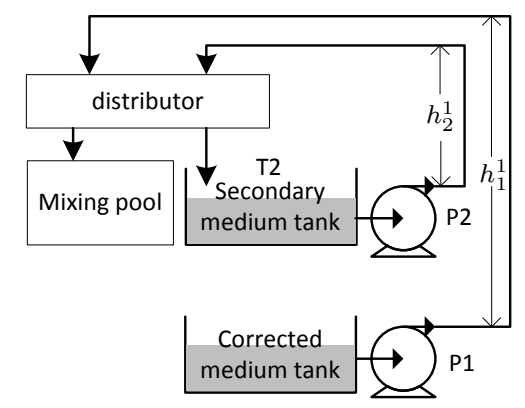

Figure 2: PSS Option 1: with a secondary tank added

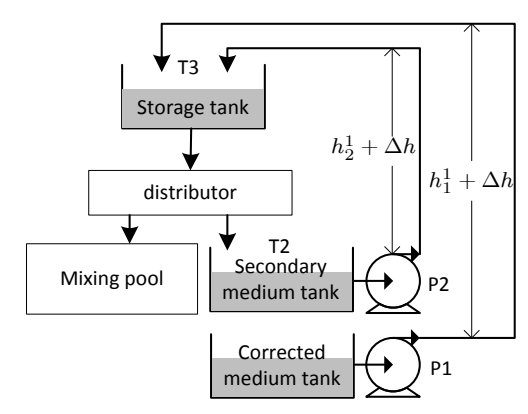

Figure 3: PSS Option 2: with a storage tank added at the top

\subsection{PSS Option 2}

From energy cost saving point of view, Option 1 detailed in Section 3.1 can be further improved. Firstly, in order to ensure the medium supply to the mixer, P2 has to have the same flow rate as the existing corrected medium pump, power reduction comes only from the decreased differential head. Secondly, the two corrected medium pumps have to work in opposite condition to supply the medium. The secondary pump must be switched off when the primary pump is switched on because there is no water storage space available in the mixer. All these limitations restrict the system's energy saving potential.

Therefore, a different configuration is presented. A new tank/reservoir (T3) is added above the dis- tributor while the secondary tank is still used. The process flow chart is given in Fig. 3 in which T3 is added.

The reasons why Option 1 is presented are stated as follows. Firstly, in some cases, it is impossible to added a T3 due to space and/or geographical limits. For instance, there is no space available or lack of supporting infrastructures for an additional T3. Secondly, the T3 added results in differential head increase due to the height of T3 in comparison to Option 1. In cases only tall $\mathrm{T} 3$ with a small storage volume is applicable, Option 1 will be a better option.

Both options presented in this section are motivated by recirculating the dense medium in an added loop with a shorter differential head in comparison to the existing configuration. The energy savings are achieved by the reduced pump power due to the reduced differential head. The energy cost savings can also be obtained from the optimal operation of the system. The system can be operated in such a way that the over-pumped medium are stored to shift load from high tariff period to low tariff period to cope with electricity shortage in peak hours.

The medium might settle in the added tank, which will influence the relative density of the medium and therefore product quality. This problem is not studied here because the settlement can be avoided by engineering methods. For instance, the medium can be supplied to a magnetite separator before entering the storage tank. The water outlet of the magnetite separator can be stored in the added tank and the magnetite can be stored in an extra container. When the stored medium is required to be supplied to the distributor, the magnetite and water can be blended again to form the medium with specified density.

\section{System dynamics}

The medium supply to the distributor is kept the same as the flow rate of the existing system to maintain the dense medium supply to the cyclone process. In addition, the coal washing plant only operates fixed speed pumps, therefore only fixed speed pumps are considered in the dynamic models. 


\subsection{PSS Option 1}

The water volume change in $\mathrm{T} 2$ can be formulated according to its mass balance as follows

$$
\begin{aligned}
\frac{d V_{2}}{d t} & =\left(Q_{1} u_{1}(t)+Q_{2} u_{2}(t)-Q_{3}\right)-Q_{2} u_{2}(t) \\
& =Q_{1} u_{1}(t)-Q_{3},
\end{aligned}
$$

where $V_{2}$ is medium volume in T2, $Q_{1}, Q_{2}$ and $Q_{3}$ are the flow rate of the primary corrected medium pump (P1), the added pump (P2), and the flow rate required at the mixing box, respectively. The control variables $u_{1}(t)$ and $u_{2}(t)$ are the on/off status of $\mathrm{P} 1$ and P2:

$$
u_{1}(t)=\left\{\begin{array}{l}
0, \mathrm{P} 1 \text { is off; } \\
1, \mathrm{P} 1 \text { is on. }
\end{array} \quad u_{2}(t)=\left\{\begin{array}{l}
0, \mathrm{P} 2 \text { is off; } \\
1, \mathrm{P} 2 \text { is on }
\end{array}\right.\right.
$$

The differential heads of the $\mathrm{P} 1$ and $\mathrm{P} 2$, as shown in Fig. 2, are $h_{1}^{1}$ and $h_{2}^{1}$, respectively.

\subsection{PSS Option 2}

The volume variation of $\mathrm{T} 2$ and $\mathrm{T} 3$ in this scheme can be written as

$$
\begin{aligned}
\frac{d V_{2}}{d t} & =\left(Q_{1}-Q_{3}\right)-Q_{2} u_{2}(t), \\
\frac{d V_{3}}{d t} & =Q_{1} u_{1}(t)+Q_{2} u_{2}(t)-Q_{1},
\end{aligned}
$$

where $V_{3}$ is the medium in T3.

In this case, as the introduction of T3 will increase the differential head of the pumping system, this is modeled by

$$
\begin{aligned}
& h_{1}^{2}=h_{1}^{1}+\Delta h, \\
& h_{2}^{2}=h_{2}^{1}+\Delta h,
\end{aligned}
$$

where $\Delta h$ is the differential head equals to the height of the T3:

$$
\Delta h=\frac{4 V_{3}^{\max }}{\pi d_{T}^{2}},
$$

in which $d_{T}$ is the diameter and $V_{3}^{\max }$ is the maximum volume of $\mathrm{T} 3$.

\subsection{Operational constraints}

For Option 1, there are volume limit on the secondary corrected medium tank, flow rate and operating time limit for P2. Besides, the control variables are binary signals for the on/off status of the pumps.

$$
\begin{aligned}
& V_{2}^{\min } \leq V_{2} \leq V_{2}^{\max }, \\
& Q_{1}=Q_{2}, \\
& u_{1}(t)+u_{2}(t)=1, \\
& u_{1}(t), u_{2}(t) \in\{0,1\} .
\end{aligned}
$$

As for Option 2, operational constraints are volume limits on T2 and T3. Also, the control variables are required to be binary integers.

$$
\begin{aligned}
& V_{2}^{\text {min }} \leq V_{2} \leq V_{2}^{\text {max }}, \\
& V_{3}^{\text {min }} \leq V_{3} \leq V_{3}^{\text {max }}, \\
& u_{1}(t), u_{2}(t) \in\{0,1\} .
\end{aligned}
$$

\section{Optimal operation under time-based elec- tricity tariffs}

Time-base electricity tariffs like time-of-use (TOU) tariff are commonly used all over the world nowadays [23]. The optimal operation of the proposed PSS in coal beneficiation plant is formulated under such tariff.

The objective of the optimization is to minimize energy cost while maintaining the normal production process, therefore, the following objective function is used

$$
J=\int_{0}^{T} p(t)\left(P_{1} u_{1}(t)+P_{2} u_{2}(t)\right) d t
$$

where $T$ is the total operation time during a day, $p(t)$ is the electricity price at time $t$ and $P_{1}$ and $P_{2}$ are the power of P1 and P2 (kW), respectively [24]. For Option $1, P_{1}=\frac{Q_{1} \rho g h_{1}^{1}}{1000 \eta_{p} \eta_{m}}, P_{2}=\frac{Q_{2} \rho g h_{2}^{1}}{1000 \eta_{p} \eta_{m}}$. For Option $2, P_{1}=\frac{Q_{1} \rho g h_{1}^{2}}{1000 \eta_{p} \eta_{m}}, P_{2}=\frac{Q_{2} \rho g h_{2}^{2}}{1000 \eta_{p} \eta_{m}}$. Coefficients $\eta_{p}$ and $\eta_{m}$ are pump and motor efficiency, $\rho$ is the density of the dense medium and $g$ is gravity acceleration.

Then the optimization problem with Option 1 is to minimize (7) subject to (1) and (5). For Option 2, the problem is to minimize (7) subject to (2) and (6). This is solved by mixed integer programming method in this study.

\section{Life cycle cost analysis}

Economic benefit of the introduced PSS is evaluated by comparing life cycle cost (LCC) of the introduced PSS configuration and the existing system. In this section, the LCC models for pre- and postimplementation of the PSS scheme are developed. Present value method is employed to estimate the L$\mathrm{CC}$ as it is widely used in economics to compare cash flows at different times and in engineering to evaluate the feasibility of the proposed design [25, 26, 27, 28]. 


\subsection{Post-implementation of PSS}

The life cycle cost by adopting the PSS scheme can be calculated as

$$
\mathrm{LCC}=C C+O C+M C-S V,
$$

where $C C, O C, M C$ and $S V$ are, respectively, capital cost, operating cost, maintenance cost and salvage value.

Adopting the present value model yields the following [28]

$$
\mathrm{LCC}=C C+\sum_{i=1}^{n} \frac{O C_{i}+M C_{i}}{(1+r)^{i}}-S V,
$$

where $i$ is the number of year, $n$ is the project lifetime and $r$ is the discount rate.

Operating cost in this study is electricity cost due to running of pumps, therefore it can be obtained by

$$
O C_{i}=365 n_{c} \int_{0}^{T} p_{i}(t)\left(P_{1} u_{1}(t)+P_{2} u_{2}(t)\right) d t
$$

where

$$
p_{i}(t)=(1+q)^{i} p(t)
$$

denotes the electricity tariff in the $i$-th year, $q$ is the percentage of annual electricity price increase and $n_{c}$ is the number of cyclone modules in the plant.

Maintenance cost and salvage value are calculated by $[25,29]$

$$
\begin{aligned}
& M C_{i}=m C C, \\
& S V=\frac{(1-d)^{n} C C}{(1-r)^{n}},
\end{aligned}
$$

where $m$ is maintenance ratio and $d$ is the annual deprecation ratio of the facilities.

\subsection{Pre-implementation of PSS}

As the baseline, the cost of the existing system during the life cycle of the PSS scheme is calculated as follows

$$
\mathrm{LCC}^{0}=\sum_{i=1}^{n} \frac{O C_{i}^{0}+M C_{i}^{0}}{(1+r)^{i}}-S V^{0},
$$

where $O C_{i}^{0}=365 n_{c} \int_{0}^{T} P_{1} p_{i}(t) d t, S V^{0}=\frac{C C^{0}(1-d)^{n-1}}{(1+r)^{n}}$, in which $C C^{0}$ is the costs of pumps in the existing system.

\subsection{Payback period}

Payback period is commonly used in economic analysis for its simplicity. It is a measure of the time in which the initial cash outflow of an investment is expected to be recovered from the cash inflows generated by the investment. To take the time value of money into consideration, the discounted payback period is employed to evaluate the proposed approach's financial viability and feasibility [30]. The following formula is used to calculate the payback period:

$$
\text { Payback period }=n_{y}+\frac{\sum_{i=1}^{n_{y}}\left(\operatorname{LCC}^{0}(i)-\operatorname{LCC}(i)\right)}{\operatorname{LCC}\left(n_{y}+1\right)},
$$

where $n_{y}$ is the last year with a negative cumulative cash flow.

Note that cash flow in this study is the difference between the LCC pre-implementation of the PSS options and the LCC post-implementation of the PSS options.

\section{Case study}

To demonstrate the feasibility and effectiveness of the proposed system. Case studies are done based on the situation of a real coal washing plant. The operation optimization problem is solved in Matlab using the CPLEX toolbox function cplexbilp, which solves binary integer programming problems.

\subsection{Project configurations and parameters}

The operation status of a coal washing plant in South Africa is used without losing generality. Under different plant parameters, the performance of the proposed approach will vary in terms of the absolute savings but the energy and cost saving potential will not be affected. The studied mine operates two coal washing plants with total 15 cyclone modules. There is one corrected medium pump in each cyclone module. For the first washing plant, it consists of ten cyclone modules with $200 \mathrm{~kW}$ pumps. Five $201 \mathrm{k}-$ W pumps are running in the second washing plant. Regarding the over-pumping effect of the corrected medium pump, only $25 \%$ of the medium pumped to the distributor flows into the mixing box while the other $75 \%$ simply flows back to the corrected medium tank. The plant is run for about 16 hours every day from 6 am to $10 \mathrm{pm}$.

Other parameters are listed in Table 1. To align with the current plant operation status, the sampling period of the system $T_{s}$ is set to be 0.5 hour. 


\begin{tabular}{ccccc}
\multicolumn{5}{c}{ Table 1: Parameters } \\
\hline$Q_{1}\left(\mathrm{~m}^{3} / \mathrm{s}\right)$ & $H_{1}(\mathrm{~m})$ & $H_{2}(\mathrm{~m})$ & $\eta_{p}$ & $\eta_{m}$ \\
\hline 0.0859 & 60 & 20 & 0.8 & 0.6 \\
\hline
\end{tabular}

Both energy savings and electricity cost savings are calculated in comparison with the original configuration (current practice) in the following sections. The originally used pump is a fixed speed pump with a flow rate of $0.0859 \mathrm{~m}^{3} / \mathrm{s}$.

The Eskom's TOU tariff for large industrial users is used. The off-peak period is during lam to $6 \mathrm{am}$ and $11 \mathrm{pm}$ to $12 \mathrm{pm}$, peak period is during $8 \mathrm{am}$ to $10 \mathrm{am}$ and $7 \mathrm{pm}$ to $8 \mathrm{pm}$, Other time is standard period. The electricity prices for off-peak, standard and peak period are R0.3558/kWh, R0.5948/kWh and $\mathrm{R} 2.0538 / \mathrm{kWh}$, respectively. The current unit R used in this study is the South African Rand, the average exchange of Rand to US dollar in 2012 is $\$ 1=R 8.21$.

\subsection{Results of PSS Option 1}

In this subsection, the impacts of the added secondary corrected medium tank/reservoir are investigated.

With the capacity limits of $\mathrm{T} 2$ set to $V_{2}^{\max }=160$ $\mathrm{m}^{3}$ and $h_{2}^{1}=20 \mathrm{~m}$, the simulation results are shown in Fig. 4.

The total operation time of $\mathrm{P} 1$ is 4 hours, it is switched off to save energy during the other 12 hours when the added P2 is responsible for the medium supply. It can be seen that the secondary pump P2 is turned on as long as possible because it has a smaller power due to the reduced differential head compared to the original pump P1. The three to one operation time of $\mathrm{P} 2$ and $\mathrm{P} 1$ can be explained by the $75 \%$ overpumping of $\mathrm{P} 1$ as $(16-4) / 16=0.75$.

Regarding load shifting effect, it can be observed from the first subplot that the secondary pump P2 is switched on at most of the time, P1 is switched on only when the medium stored in the secondary tank $\mathrm{T} 2$ is insufficient to supply the cyclone process.

The energy consumption and electricity cost decreased by $50.00 \%$ and $51.71 \%$, respectively under this option. This yields a daily R1715 electricity cost reduction per cyclone module. In addition, since the coal mine is contracted to the power station, the energy consumption reduction can enable the power station to have a higher capacity to supply other consumers and the electricity cost reduction also means fuel cost reduction for the power plant.

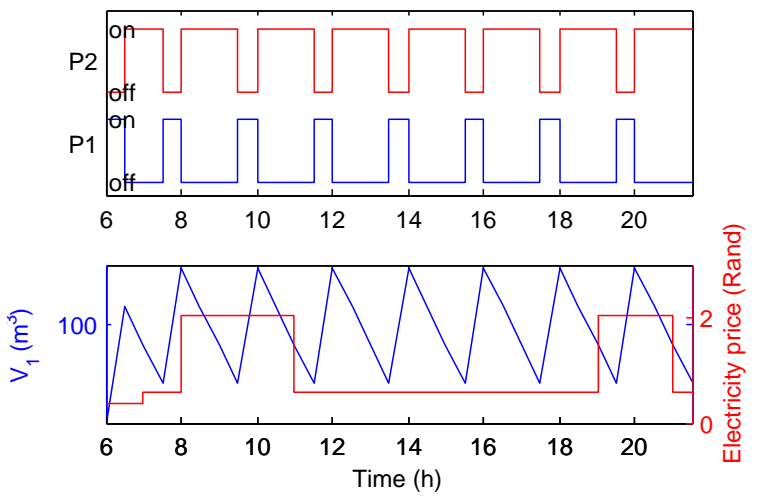

Figure 4: Results of Option 1 with $V_{2}^{\max }=160 \mathrm{~m}^{3}$

\subsection{Results of PSS Option 2}

In this configuration, a start-up procedure is presented to minimize the size of $\mathrm{T} 2$ because of following reasons.

Firstly, P2 cannot start working before there is some medium in $\mathrm{T} 2$. That is to say, if there is no medium in $\mathrm{T} 2$ when the plant starts to operate, $\mathrm{P} 2$ must be kept off in the first sampling period. Secondly, if the P2 is kept off during the first sampling period, the storage capacity of the $\mathrm{T} 2$ must be at least $\left(Q_{1}-Q_{3}\right) T_{s}$ according to (3). As the flow rate of the over-pumped medium by $\mathrm{P} 1$ is high, it requires a large volume $\mathrm{T} 2$ to store the over-pumped medium during a sampling period. In practice, the larger T2 the higher investment and maintenance cost, which is undesirable.

In order to reduce the size of T2, a simple start-up procedure is introduced. At start-up, P1 is turned on and $\mathrm{P} 2$ is kept off to allow T2 to store medium; after $\frac{0.8 V_{2}^{\max }}{Q_{1}-Q_{3}}$ seconds, P2 is switched on and the optimal schedule of the two pumps is implemented.

In the simulation $Q_{2}=Q_{1}-Q_{3}, V_{2}^{\max }=1 \mathrm{~m}^{3}$ and $V_{3}^{\max }=160 \mathrm{~m}^{3}$. The height of $\mathrm{T} 3$ in this case is $0.91 \mathrm{~m}$. Simulation results are shown in Fig. 5 . The zoomed in part in Fig. 5 gives a clear view of the start-up procedure.

Energy consumption saving is $50.05 \%$ and electricity cost saving is $52.23 \%$ in this case.

In comparison with the result of Option 1, more energy and electricity cost savings are achieved. Specifically, there is $0.52 \%$ more electricity cost savings in Option 2 than that of Option 1. The reason for this $0.52 \%$ saving is due to the energy storage capacity of T3. This enables the DMC process to shift load from peak period to off-peak period. 


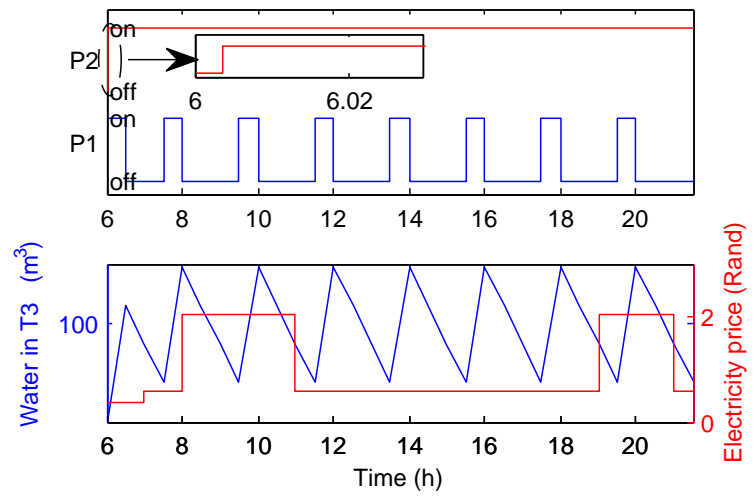

Figure 5: Results of Option 2 with $V_{3}^{\max }=160 \mathrm{~m}^{3}$

\subsection{With larger storage capacity}

In this subsection, the capacities of the added tanks are increased in order to investigate its impacts on load shifting under time based tariffs.

In Option 1, the capacity of $\mathrm{T} 2$ is set to $320 \mathrm{~m}^{3}$. For Option 2, T2 is kept with $V_{2}^{\max }=1 \mathrm{~m}^{3}$ while the limit of $\mathrm{T} 3$ is increased to $320 \mathrm{~m}^{3}$. The results are depicted by Fig. 6 and Fig. 7, respectively.

From those figures, it is clear that load shifting is very effective with a large storage tank. In both cases, the original pump P1 is switched off during peak period.

Energy saving and electricity cost saving from Option 1 are $50.00 \%$ and $58.06 \%$, respectively. When compared to the results in Section 7.2, it can be found that the energy saving remains stable while the electricity cost saved $6.35 \%$ more. This is because the required medium at the mixing box is the same. On one hand, the medium pumped up to the distributor is the same which results in the same amount of time of the on state of $\mathrm{P} 1$, as $\mathrm{P} 2$ is working in opposite with $\mathrm{P} 1$, it then leads to the same energy consumption as the result in Section 7.2. On the other hand, due to the increased storage capacity of $\mathrm{T} 2$, the operation of $\mathrm{P} 1$ can be switched off during peak periods to save energy cost.

As for the results of the PSS Option 2, energy consumption decreases by $49.68 \%$ in comparison to the existing configuration (no tank, only P1), energy cost reduction reached $61.70 \%$. More energy is consumed than the case with a smaller tank with $160 \mathrm{~m}^{3}$ volume due to the increased height of T3 (see equation (4)). By contrast, the electricity cost is further reduced as a result of the load shifting with the larger storage capacity.

In summary, electricity cost savings increase with

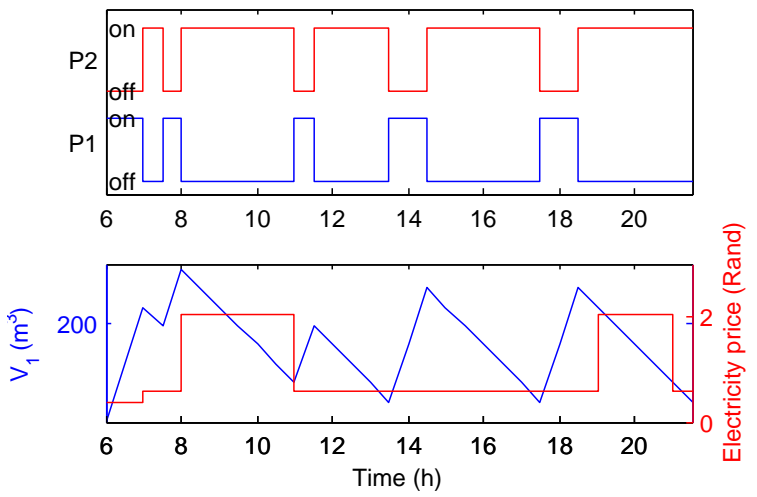

Figure 6: Results of Option 1 with $V_{2}^{\max }=320 \mathrm{~m}^{3}$
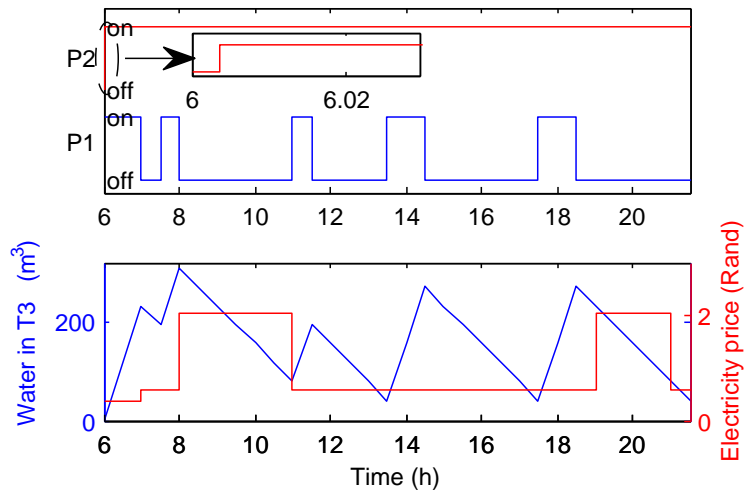

Figure 7: Results of Option 2 with $V_{3}^{\max }=320 \mathrm{~m}^{3}$

the increase of the capacity of the storage tank while energy consumption remains stable in Option 1 and increased in Option 2.

The influence of the differential head of the P2 and the diameter of T3 on the energy and cost savings are investigated and plotted in Fig. 8, in which $C_{s}$ and $E_{s}$ are the percentage reduction of energy consumption and cost, respectively. Note that this simulation is run with the larger capacity $320 \mathrm{~m}^{3}$.

As depicted by Fig. 8, both energy consumption and energy cost savings decrease when $h_{2}^{1}$ increases in the two proposed configurations. However, the two options (with and without T3) have distinct performance differences. Firstly, the smaller the $h_{2}^{1}$, the smaller difference between Option 1 and Option 2 . It is noted that then advantage of Option 2 becomes noticeable when $h_{2}^{1}$ gets larger and larger. This is evidenced by the effect that the energy cost saving drops faster without T3 when $h_{2}^{1}$ increases. Nevertheless, the energy consumption saving resulted from the two options share the same rate of change.

Moreover, the energy consumption saving yield from Option 2 is dependent on the diameter of T3, the 


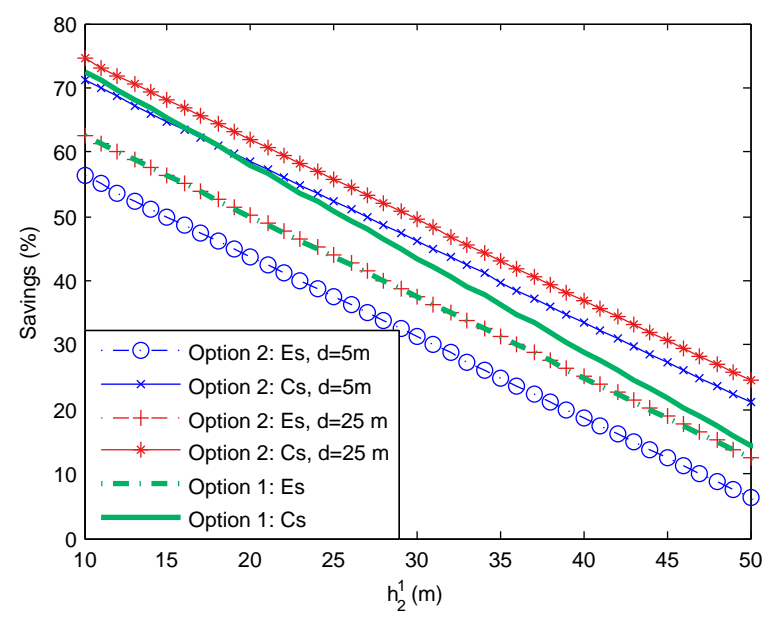

Figure 8: Saving ratios relationship to $h_{2}^{1}$

bigger the diameter, the more energy consumption savings. It is also interesting to note that if $h_{2}^{1}$ can be small enough, the performance of the Option 2 will be worse than the Option 1 in terms of both energy consumption saving and energy cost saving like the case when $h_{2}^{1}<15 \mathrm{~m}$ and $d_{T}=5 \mathrm{~m}$ in Fig. 8 .

Therefore, the two options proposed should be used according to the specific situation of the plant. Generally, the Option 2 is able to outperform Option 1. But if there is limits on the selection of the T3 and if the plant owner prefers energy consumption savings to energy cost savings, the Option 1 may offer a better solution.

\subsection{Life cycle cost analysis}

In order to show the economic viability of the proposed schemes, the following LCC analysis is given. To be conservative, the results from the smaller tank size in Section 7.2 and Section 7.3 are used in this analysis.

The economic data of the project is shown in Table 2. The capital costs of the project are based on the practical data on the installation costs of pump$\mathrm{s}$ and water tanks and are given in the second row of Table 2. For the maintenance rate, the mine under investigation replaces the slurry pumps every seven month due to performance drop. Therefore, the maintenance for the existing system is to replace the slurry pumps every seven month, which results in the high maintenance rate $(120 \%)$. In the proposed schemes, this pump replacement rate is kept the same as in the existing system while the maintenance rate for tanks is $40 \%$, which yields the results shown in the third row of Table 2.
Table 2: Summary of economic data

\begin{tabular}{llll}
\hline \hline & Existing & Option 1 & Option 2 \\
\hline Project lifetime (years) & - & 10 & 10 \\
$C C$ (million Rands) & $2.25^{1}$ & 24.41 & 26.26 \\
$M R(\%)$ & 120 & $24.54^{2}$ & $25.63^{2}$ \\
$r(\%)$ & 10 & & \\
$d(\%)$ & 50 & & \\
$q(\%)$ & 24 & & \\
\hline \hline
\end{tabular}

${ }^{1}$ This is the cost of the currently used pumps since there is no initial capital cost for the existing system.

2 The maintenance ratios after implementation of the proposed schemes are lower than that of the existing system because the maintenance ratio for tanks are much lower than for pumps.

Table 3: Summary of 10-year LCC analysis results (Rand)

\begin{tabular}{llll}
\hline \hline & Existing & Option 1 & Option 2 \\
\hline$C C$ & $2,250,000$ & $24,412,275$ & $26,262,483$ \\
$O C$ & $372,109,617$ & $179,701,589$ & $177,777,562$ \\
$M C$ & $16,590,331$ & $36,812,065$ & $41,359,556$ \\
$S V$ & 847 & 9,191 & 9,888 \\
\hline Accumulated saving & $150,032,364$ & $145,559,388$ \\
Payback period & 2.68 years & 3.30 years \\
\hline \hline
\end{tabular}

The breakdown of the result is depicted in Table 3. Although initial capital cost and maintenance cost are increased in the proposed schemes, the operating cost is decreased. In this 10-year LCC analysis, the average annual cost savings obtained by the PSS Option 1 and PSS Option 2 are R15.00 million and R14.56 million, respectively.

Besides, the LCC analysis shows that the proposed change in the beneficiation plant can result in positive economic effects on the plant with a relatively short payback period ( 2.68 years for the proposed Option 1 and 3.30 years for Option 2).

In this LCC analysis, the result shows that the Option 1 is better than Option 2 in terms of economic benefit. However, the benefits of Option 1 and Option 2 can be different under different situations. Therefore, the performance of the two options must be compared before implementation according to the given conditions.

\section{Conclusion}

A pump storage system (PSS) is introduced to coal washing plants to improve their energy efficiency. Two options of the PSS are proposed, which can be applied according to the given conditions of the plant. The system dynamics of the PSS and its corresponding optimal operation problem is formulated 
and solved. The results verified the effectiveness of the proposed system in terms of energy consumption and cost reduction. In addition, life cycle cost analysis is done to investigate the economic benefits of the scheme change. It is shown that both options are able to generate positive financial savings with short payback period. It also demonstrates that selection of the two PSS options presented must be based on the practical situation of the plant under consideration.

\section{References}

[1] Hines, P., Apt, J., Talukdar, S.. Large blackouts in North America: Historical trends and policy implications. Energy Policy 2009;37(12):5249 - 5259.

[2] de Nooij, M., Lieshout, R., Koopmans, C.. Optimal blackouts: Empirical results on reducing the social cost of electricity outages through efficient regional rationing. Energy Economics 2009;31(3):342 - 347.

[3] De Jonghe, C., Hobbs, B., Belmans, R.. Optimal generation mix with short-term demand response and wind penetration. IEEE Transactions on Power Systems 2012;27(2):830-839.

[4] Xia, X., Elaiw, A.. Optimal dynamic economic dispatch of generation: A review. Electric Power Systems Research 2010;80(8):975 - 986.

[5] Xia, X., Zhang, J., Elaiw, A.. An application of model predictive control to the dynamic economic dispatch of power generation. Control Engineering Practice 2011;19(6):638 - 648.

[6] Elaiw, A.M., Xia, X., Shehata, A.M.. Dynamic economic dispatch using hybrid DE-SQP for generating units with valve-point effects. Mathematical Problems in Engineering 2012;2012:1-10.

[7] Dahal, K.P., Chakpitak, N.. Generator maintenance scheduling in power systems using metaheuristic-based hybrid approaches. Electric Power Systems Research 2007;77(7):771 - 779 .

[8] Ekpenyong, U.E., Zhang, J., Xia, X.. An improved robust model for generator maintenance scheduling. Electric Power Systems Research 2012;92(0):29 - 36.

[9] Reihani, E., Sarikhani, A., Davodi, M., Davodi, M.. Reliability based generator maintenance scheduling using hybrid evolutionary approach. International Journal of Electrical Power \& Energy Systems 2012;42(1):434 - 439.

[10] Toledo, O., Oliveira Filho, D., Diniz, A.S.A., Martins, J., Vale, M.. Methodology for evaluation of Grid-Tie connection of distributed energy resources;case study with photovoltaic and energy storage. IEEE Transactions on Power Systems 2013;28(2):1132-1139.

[11] Wang, B.. An imbalanced development of coal and electricity industries in China. Energy Policy 2007;35(10):4959 - 4968.

[12] Zhuan, X., Xia, X.. Optimal operation scheduling of a pumping station with multiple pumps. Applied Energy 2013;104(0):250 - 257.

[13] Bagirov, A., Barton, A., Mala-Jetmarova, H., Nuaimat, A.A., Ahmed, S., Sultanova, N., et al. An algorithm for minimization of pumping costs in water distribution sys- tems using a novel approach to pump scheduling. Mathematical and Computer Modelling 2013;57(34):873 - 886.

[14] Shu, S., Zhang, D., Liu, S., Zhao, M., Yuan, Y., Zhao, H.. Power saving in water supply system with pump operation optimization. In: 2010 Asia-Pacific Power and Energy Engineering Conference. Chengdu, China; 2010,.

[15] Gong, Y., Shen, G., Zuo, K., Shi, H.. Overview of a few key issues for optimal operation of parallel pumping stations. Applied Mechanics and Materials 2012;212213(0):1217-1222.

[16] Zhao, T., Zhang, J., Ma, L.. On-line optimization control method based on extreme value analysis for parallel variable-frequency hydraulic pumps in central air-conditioning systems. Building and Environment 2012;47(0):330 - 338 .

[17] Zhuan, X., Xia, X.. Development of efficient model predictive control strategy for cost-optimal operation of a water pumping station. IEEE Transactions on Control Systems Technology 2012;:1-1.

[18] Borkowski, D., Wetula, A., Bień, A.. Design, optimization, and deployment of a waterworks pumping station control system. ISA Transactions 2012;51(4):539 - 549.

[19] Meyer, E., Craig, I.. The development of dynamic models for a dense medium separation circuit in coal beneficiation. Minerals Engineering 2010;23:791-805.

[20] Kindig, K.J.. Coal cleaning process. US patent EP0608325 A1; Genesis Research Corporation; 1994.

[21] Masuda, S., Toraguchi, M., Takahashi, T., Haga, K.. Electrostatic beneficiation of coal using a cyclonetribocharger. IEEE Transactions on Industry Applications 1983;IA-19(5):789-793.

[22] Kohler, J., Sottile, J., Placha, D.S.. Process control of heavy-media systems for coal-preparation plants. IEEE Transactions on Industry Applications 1987;IA-23(2):382388.

[23] Ashok, S., Banerjee, R.. Load-management applications for the industrial sector. Applied Energy 2000;66(2):105 111.

[24] Bernier, M.A., Bourret, B.. Pumping energy and variable frequency drives. ASHRAE Journal 1999;41(12):37-40.

[25] Ong, H., Mahlia, T., Masjuki, H., Honnery, D.. Life cycle cost and sensitivity analysis of palm biodiesel production. Fuel 2012;98(0):131 - 139.

[26] Leckner, M., Zmeureanu, R.. Life cycle cost and energy analysis of a net zero energy house with solar combisystem. Applied Energy 2011;88(1):232 - 241.

[27] Cople, D.G., Brick, E.S.. A simulation framework for technical systems life cycle cost analysis. Simulation Modelling Practice and Theory 2010;18(1):9 - 34 .

[28] Fabrycky, W.J., Blanchard, B.S.. Life-cycle Cost and Economic Analysis. Prentice-Hall; 1991.

[29] Dellísola, A., Kirk, S.. Life Cycle Costing for Facilities. John Wiley \& Sons; 2003.

[30] Yard, S.. Developments of the payback method. International Journal of Production Economics 2000;67(2):155 167. 